\title{
Recommendations for Scholarly Work in Medical Journals
}

\section{Baral G}

Chief Editor, NJOG

Received: March 12, 2015 ; Accepted: July 05, 2015

ABSTRACT

Creating and publishing a scientific paper should be guided by the set guidelines. Authors should be responsible to evaluate integrity of journals by their behavior.

The conduct, reporting, editing and publication of scholarly work in medical journals should comply with the recommendations made by International Committee of Medical Journal Editors (ICMJE). ${ }^{1}$ It is developed to help authors, reviewers, editors and publishers to create an ethically sound and scientifically accurate publication. It is the most useful guideline to the authors and they also have to follow the specific guidelines of particular journal for the submission. Every author may choose different types of study designs as per their condition even for the same title and they have to learn how to report those studies accordingly. Thus for the reporting guidelines for the specific study types are provided by Equator Network. ${ }^{2}$ Health professionals may belong to different specialty and they need specific types of reporting system to convey their specific message. Then the specialty-specific reporting guidelines will help specialist authors on their own field of work. ${ }^{3}$ Authors may also be misguided by some journals known as predatory journals that may not exist and the submission would not be viable. Therefore the scientific existence has to be evaluated by authors themselves. It will be sorted out by the set guidelines. ${ }^{4}$

Therefore the publication practice is not the easy job neither a secured field. It warns everyone to be skeptical based on scientific norms.

\section{REFERENCES}

1. Recommendations for the conduct, reporting, editing, and publication of scholarly work in medical journals. ICMJE. Dec 2016; http://www.icmje.org/icmje-recommendations.pdf

2. Reporting guidelines for main study types. Available at: http:// www.equator-network.org/

3. Browse reporting guidelines by specialty. http://www. equator-network.org/library/browse-reporting-guidelines-byspecialty/

4. Laine C,Winker MA. Identifying predatory or pseudojournals. Available at: http://www.wame.org/identifyingpredatory-or-pseudo-journals

\section{CORRESPONDENCE}

Prof. Gehanath Baral Chief Editor, NJOG gehanath@gmail.com njogeditor@gmail.com 